\title{
Penggunaan E-wallet di Kalangan Mahasiswa
}

\author{
Hizbul Hadi Nawawi \\ Universitas Hasanuddin \\ hizbulhadi146@gmail.com
}

\begin{abstract}
Internet users are growing rapidly from time to time throughout the world, including Indonesia. As a result, consumer needs in terms of making payments have changed towards non-cash payments, namely e-wallets, which have become a huge potential in the e-commerce market. The preference for e-wallet transactions is increasing compared to using cash on hand. Most of its users are millennials, including students. This study examines knowledge related to the use of e-wallets and the reasons behind its use.
\end{abstract}

The study involve ten college students, consisting of nine female students, and a male student whose age varies between 19 and 23 years. They come from various universities. Using qualitative approach, this study use in-depth interview as the primary data collection technique and secondary data obtained from relevant website.

This research shows that $e$-wallet is not only understood as a place to store money electronically, but also as a digital payment. In Indonesia there are various e-wallet products. Among others OVO, Gopay, and DANA are the most popular ones. There are three aspects related to the students' knowledge about e-wallet: source of information, features, and its use. Advertisements from social media, television, and transportation applications are the main sources of information about e-wallets. E-wallet offered various features, such as topping up, paying bills and pulses, and transferring and withdrawing from e-wallets to bank partners. E-wallet is used for a variety of purpose, such as to pay online transportation, to buy food/drinks, to pay bills, etc. There are three basic reasons why students use e-wallet as a payment method, namely because of the promos offered, convenience in transactions, and ease to operate. To attract people to use e-wallets, service providers must work with various merchants, whose promos are increasingly attracting users to use e-wallet for payment. In using e-wallets, students not only feel comfortable, but also convenience in payment because it can be done anywhere as long as the user is connected to the internet.

Keywords : Millenial generation, students, e-wallet, internet, cashless, and digital payment.

\footnotetext{
Pendahuluan

Pengguna internet berkembang pesat dari waktu ke waktu di seluruh dunia, termasuk Indonesia (lihat Gambar 1). Ini artinya kebutuhan konsumen dalam hal melakukan pembayaran telah mengalami perubahan menuju kepada pembayaran modern yakni cashless payment.
} 


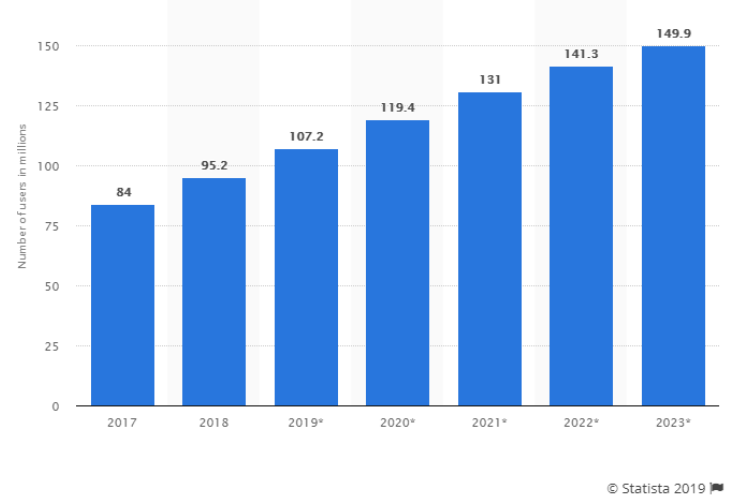

Gambar 1. Data pengguna internet di Indonesia dan proyeksinya ${ }^{1}$

Di Indonesia telah berkembang sistem pembayaran berbasis online dengan menggunakan uang elektronik (e-money). Sejak tanggal 14 Agustus 2014, Bank Indonesia telah mencanangkan Gerakan Nasional Non Tunai (GNNT). Hal ini tidak lain adalah dampak dari perkembangan teknologi yang begitu pesat secara global. Akibatnya, bank swasta maupun negara berlomba-lomba dalam meluncurkan produk mereka. Bank BRI, misalnya, mengeluarkan e-money yang diberi nama Brizzi, Bank BNI dengan produknya Tap Cash, Bank Mandiri dengan produknya Mandiri e-money, dan Flash \& Sakuku dari BCA, bahkan provider telekomunikasi juga ikut andil dalam mengeluarkan produknya seperti Telkomsel dengan produk andalannya T-Cash.

E-wallet (dompet elektronik) merupakan salah satu bentuk Fintech (Finance Technology) yang memanfaatkan media internet dan digunakan sebagai salah satu alternatif metode pembayaran. E-wallet muncul menawarkan lebih banyak kemudahan dengan teknologi terkini yang dapat diakses oleh semua kalangan. Indonesia saat ini memiliki generasi millenial, mereka yang kebanyakan remaja telah mengenal dan mengadopsi teknologi. Akses terhadap internet telah dapat dinikmati hampir di setiap kalangan di seluruh penjuru negeri. Hal ini merupakan peluang yang sangat menjanjikan di era industri 4.0 bagi industri perbankan dan $e$ commerce dalam mengembangkan usaha mereka.
Meskipun pembayaran tunai masih dilakukan, preferensi pembayaran dengan sistem digital sedang populer dan e-wallets adalah satu di antaranya yang berpotensi besar di pasar e-commerce. E-commerce dan $e$ money menjadi partner yang kuat dalam industri 4.0 ini. Kemudahan berbelanja, bertransaksi dan top up saldo menjadi kunci keberhasilan dari kedua produk teknologi ini. Dalam kaitan dengan pembayaran digital pada transaksi e-commerce, Marita (2012:105) menjelaskan bahwa dalam bertransaksi via internet dibutuhkan sebuah prosedur dan tempat bertemunya penjual dan pembeli. Studi Mulyasari dkk. (2014:167) menunjukkan bahwa alat pembayaran yang biasanya disediakan dalam bertransaksi pada $e$ commerce mencakup kartu kredit online, dompet digital (e-wallet), tunai digital, storedvalued online, digital accumulating, pembayaran cek digital dan sistem pembayaran wireless.

E-commerce di era saat ini telah mulai banyak diminati oleh masyarakat karena masyarakat juga telah banyak meluangkan waktu pada gadget mereka masing-masing. Di dalam dunia e-commerce terdapat dua pelaku, yaitu merchant yang menyediakan barang/jasa (penjual) dan buyer/customer yang melakukan transaksi pembelian (pembeli), sebagaimana pelaku transaksi pada umumnya, baik sebagai merchant maupun buyer/customer, pengetahuan yang mendasar tentang cara belanja dan juga cara pembayaran akan mendukung pengambilan keputusan yang tepat bagi keduanya saat memulai aktifitas $e$ commerce (Marita 2012:107).

E-commerce tak terlepas dari mahasiswa. Mereka umumnya selalu ingin bergaya hidup up to date serta konsumtif, dan untuk pemenuhan itu, mereka meluangkan banyak waktunya dengan gadget mereka untuk melihat barang-barang apa saja yang terbaru dan tersedia di situs belanja online. Promo berupa diskon yang diberikan oleh merchant menjadi daya tarik tersendiri (baca, misalnya, Kusnawan dkk. 2019). Ini mengindikasikan bahwa strategi pemberian diskon sangat memengaruhi minat beli

\footnotetext{
${ }^{1}$ https://qwords.com/blog/sejarah-singkat-internet/, diakses tanggal 29 Desember 2020.
} 
konsumen. Studi Fransiska dan Suyasa (2017) menunjukkan bahwa konsumen memiliki pola perilaku berbeda pada setiap metode pembayaran. Pengguna uang tunai lebih dapat membatasi pengeluarannya dibandingkan pengguna kartu kredit. Namun, pengguna kartu kredit merasa bebas berbelanja tanpa membawa uang. Hal ini menjadi faktor yang sangat kuat dalam mendukung gaya hidup konsumerisme konsumen.

Menurut Anjelina (2018), pengguna menggunakan e-money karena beberapa faktor, yaitu: subjective norm (orang yang dianggap penting bagi konsumen, menentukan konsumen untuk menggunakan e-money); social image (konsumen menggunakan $e$ money untuk meningkatkan reputasi sosial mereka), dan perceived benefit, menjadi faktor penentu konsumen menggunakan e-money karena memudahkan aktifitas transaksi mereka. Namun, Maulinda (2016:70) beranggapan, bahwa kehadiran e-money setidaknya memiliki 5 karakteristik, yaitu: praktis, cepat, nyaman, mudah, dan aman telah membangun kepercayaan (trust) masyarakat untuk beralih dari cash society ke cashless society dan memahami bahwa kehadiran e-money sebagai perubahan sosial kultural dan interaksional. Ini diperkuat oleh temuan Suharni (2018) bahwa peningkatan penggunaan e-money membawa perubahan pemikiran masyarakat mengenai konsep kebendaan. Pada awalnya masyarakat hanya menganggap e-money sebagai kartu biasa, kini e-money dianggap sebagai alat pembayaran praktis yang modern, karena metode pembayarannya menggunakan teknologi terkini, dan akurat sehingga jumlah saldo yang terpotong sesuai dengan nominal barang tersebut. Namun, studi Subaramaniam dkk. (2020), yang mengevaluasi dampak positif dan negatif dari $e$-wallet bagi pengguna, menunjukkan bahwa kesadaran adalah kunci bagi pengguna untuk mengurangi dampak negatif penggunaannya.

Mahasiswa saat ini identik dengan lifestyle yang up to date, sehingga dapat dikatakan bahwa mereka merupakan konsumen yang banyak melakukan aktifitas jual-beli di pasaran. Perkembangan teknologi khususnya pada Fintech (financial technology) membuat mahasiswa mulai beralih pada produk tersebut dalam melakukan transaksi perbelanjaan.

Pembahasan dalam artikel ini terbagi atas dua sesi. Pertama, diskusi difokuskan pada pengetahuan mahasiswa tentang $e$-wallet dari sumber informasinya, fitur-fitur yang dimiliki, dan penggunaan dari e-wallet itu sendiri. $K e d u a$, mengeksplorasi alasan penggunaan $e$ wallet di kalangan mahasiswa.

\section{Metode Penelitian}

Penelitian ini dilakukan antara bulan September 2019 dan Februari 2020 di kota Makassar, kota metropolitan dengan penduduk yang multi-etnis. Umumnya masyarakat perkotaan menjadi trend setter dalam berbagai aspek, terutama terkait dengan gadget dan penggunaannya yang menjadi salah satu indikator bahwa mereka adalah generasi millenial.

Informan dari penelitian ini terdiri sepuluh orang yang semuanya berstatus mahasiswa/i, dan terdiri atas sembilan mahasiswi dan seorang mahasiswa dan berusia antara 19 dan 23 tahun. Mereka berasal dari lima universitas yang berbeda, yakni Universitas Hasanuddin (UNHAS), Universitas Bosowa (UNIBOS), Universitas Negri Makassar (UNM), Universitas Fajar (UNIFA), dan Universitas Muslim Indonesia (UMI), sebagaimana dijabarkan dalam Tabel 1 berikut ini.

\begin{tabular}{|c|c|c|c|c|c|}
\hline \multicolumn{7}{|c|}{ Tabel 1.Informan Penelitian } \\
\hline & $\begin{array}{c}\text { Nama Informan } \\
\text { (disamarkan) }\end{array}$ & $\begin{array}{c}\text { Jenis Kelamin } \\
\text { (L/P) }\end{array}$ & Umur & Status & Institusi \\
\hline 1. & Ollaf & $\mathrm{L}$ & 19 & Mahasiswa & UNHAS \\
\hline 2. & Desy & $\mathrm{P}$ & 20 & Mahasiswa & UNHAS \\
\hline 3. & Heny & $\mathrm{P}$ & 21 & $\begin{array}{c}\text { Barista \& } \\
\text { Mahasiswa }\end{array}$ & UNHAS \\
\hline
\end{tabular}




\begin{tabular}{|c|c|c|c|c|c|}
\hline 4. & Sri & P & 21 & Mahasiswa & UNIBOS \\
\hline 5. & Irma & P & 21 & Mahasiswa & UNIBOS \\
\hline 6. & Nunu & P & 19 & Mahasiswa & UNM \\
\hline 7. & Sinta & P & 19 & Mahasiswa & UNM \\
\hline 8. & Wenny & P & 19 & Mahasiswa & UNIFA \\
\hline 9. & Mala & P & 23 & Mahasiswa & UMI \\
\hline 10. & Pipi & P & 23 & Mahasiswa & UMI \\
\hline
\end{tabular}

Dalam penelitian ini data primer diperoleh melalui teknik wawancara mendalam (in-depth interview) dan data sekunder diperoleh masing-masing website/aplikasi penyedia jasa e-wallet, yakni: www.ovo.id, www.dana.id, dan www.gojek.com/gopay/. Teknik in-depth interview digunakan untuk memeroleh data tentang pengetahuan mahasiswa terkait $e$ wallet dan mengapa mereka menggunakan $e-$ wallet dalam bertransaksi. Data sekunder dari website/aplikasi dari masing-masing penyedia jasa e-wallet digunakan untuk mengetahui jenis layanan dari aplikasi yang ditawarkan kepada konsumen.

Analisis data dimulai dengan membaca keseluruhan data yang diperoleh dari data primer (in-depth interview) dan data sekunder (layanan website/aplikasi penyedia data $e$ wallet). Ini dilanjutkan dengan mendeteksi tema-tema yang muncul, yakni pengetahuan mahasiswa tentang e-wallet, sumber informasi tentang e-wallet, ragam fitur e-wallet, penggunaan e-wallet, dan alasan menggunakan e-wallet. Ini kemudian dilanjutkan dengan melakukan coding. Selanjutnya, data tersebut lalu dinarasikan, diinterpretasi, dan dimaknai.

Etika dalam penelitian ini terbagi atas tiga tahap. Tahap pertama, pra lapangan, yakni dengan mengurus izin penelitian melalui otoritas setempat yaitu PTSP (Pelayanan Terpadu Satu Pintu). Tahap kedua, saat di berada lapangan. Tahap ini meliputi tiga aspek, yakni menjelaskan kepada informan tentang maksud, tujuan, dan manfaat penelitian ini; meminta kesediaan prospektif informan untuk diwawancarai; dan hanya jika mereka bersedia untuk diwawancarai, maka akan dilanjutkan dengan meminta izin untuk merekam wawancara. Semua informan memberikan izinnya untuk diwawancarai. Tahap ketiga, pasca lapangan, yakni tahap penulisan, yang meliputi tiga aspek, yakni: menyamarkan nama informan (pseudonym), menjaga kerahasiaan informasi (siapa menginformasikan apa)(confidential); dan melalui publikasi informan dapat mengakses informasi yang telah diberikan selama penelitian berlangsung.

\section{Generasi Millenial dan E-money}

Generasi millenial yang dikenal dengan generasi $\mathrm{Y}$, dan merupakan generasi yang mendapat banyak perhatian dari berbagai bidang. Terdapat dua generasi sebelumnya, yaitu baby boom generation yang lahir antara tahun 1943 dan 1960 dan generasi X yang lahir antara tahun 1961 dan 1981. Generasi Y lahir setelah generasi X antara tahun 1982 dan 2004. Ini kemudian disusul oleh generasi Z (homeland generation) yang lahir di kisaran tahun 2005 hingga sekarang (lihat Tabel 2). Kehidupan generasi milenial tidak terlepas dari teknologi komunikasi dan informasi, khususnya internet, dan hiburan/budaya pop/musik yang telah menjadi kebutuhan pokok mereka (Juditha dan Darmawan 2018:95). Peningkatan penggunaan dan keakraban dengan komunikasi, media, dan teknologi digital merupakan ciri dari generasi millenial (Budiati dkk. 2018:18).

Tabel 2. Millenial Generation

\begin{tabular}{|l|l|l|}
\hline $\begin{array}{l}\text { Baby Boom } \\
\text { Generation }\end{array}$ & $\begin{array}{l}\text { Prophet } \\
\text { (Idealist) }\end{array}$ & $\begin{array}{l}1943- \\
1960\end{array}$ \\
\hline $\begin{array}{l}13^{\text {th }} \text { Generation } \\
(\text { Generation X) }\end{array}$ & $\begin{array}{l}\text { Nomad } \\
\text { (Reactive) }\end{array}$ & $\begin{array}{l}1961- \\
1981\end{array}$ \\
\hline $\begin{array}{l}\text { Milenial } \\
\text { Generation } \\
(\text { Generation Y) }\end{array}$ & Hero (Civic) & $\begin{array}{l}1982- \\
2004\end{array}$ \\
\hline $\begin{array}{l}\text { Homeland } \\
\text { Generation } \\
(\text { Generation Z) }\end{array}$ & Artist & $\begin{array}{l}\text { 2005- } \\
\text { present }\end{array}$ \\
\hline
\end{tabular}


Sumber: Sulistyawati dan Santosa

(2019:25).

Generasi millenial lahir di era kemajuan teknologi, perilaku Gen $Y$ ini amat sangat bergantung dengan teknologi internet untuk mencari beragam informasi sebelum mengambil keputusan untuk pembelian suatu produk atau menggunakan suatu jasa. Mereka memiliki pandangan positif tentang bagaimana teknologi dan informasi memengaruhi kehidupan mereka daripada generasi sebelumnya, mereka dapat melakukan segala aktifitas dengan sangat mudah berkat bantuan dari teknologi tersebut (Hidayatullah, dkk. 2018:242). Kehadiran generasi millenial di Indonesia dapat mendukung dalam menggairahkan industri kreatif berbasis teknologi. Generasi milenial memiliki gaya yang cukup khas, yaitu, pertama, tidak dapat jauh dari gadget mereka, mulai dari bangun tidur di pagi hari, hingga hendak tidur di malam hari; kedua, mereka lebih menyukai pembayaran cashless, dan kartu kredit atau e-wallet umumnya dan ini telah menjadi bagian gaya hidup mereka; ketiga, umumnya mereka pengguna media sosial, yang menjadi media mereka untuk berekspresi di dunia maya (Rudiwantoro 2018:44).

Gaya hidup online nampaknya telah menjadi bagian dari jati diri generasi millenial. Barang-barang branded sudah tidak asing lagi bagi mereka, di mana mereka rela membeli barang KW untuk tampil stylish di depan teman-temannya. Generasi millenial merupakan konsumen yang mendominasi pasar saat ini, sehingga hal ini bahkan bisa menjadi peluang bisnis yang sangat menjanjikan bagi mereka jika ingin memulai suatu usaha. Generasi millenial cenderung lebih konsumtif dalam menghabiskan uang untuk suatu produk atau menggunakan jasa yang telah disediakan (Hidayatullah dkk. 2018:242).

Uang elektronik (e-money) pada hakikatnya merupakan uang tunai tanpa fisik (cashless money), yang nilai uangnya berasal dari nilai uang yang disetor terlebih dahulu

2 https://www.bi.go.id/id/sistempembayaran/instrumen- kepada penerbitnya (penyedia jasa). Ini kemudian disimpan secara elektronik dalam suatu media elektronik berupa server atau kartu chip, yang berfungsi sebagai alat pembayaran non-tunai kepada pedagang yang bukan penerbit e-money yang bersangkutan (Suharni 2018:22).

E-wallet (dompet digital) adalah suatu layanan atau platform yang memberikan layanan layaknya dompet, yaitu wadah untuk menyimpan uang, namun uang yang tersimpan bersifat digital (online). E-wallet juga merupakan bagian dari fintech. Bank Indonesia melalui situs website resminya mengategorikan e-wallet itu sebagai e-money yang bersifat server based. E-money sendiri terbagi atas dua kategori, yaitu chip based dan server based dengan masing-masing produknya (lihat Gambar 2).

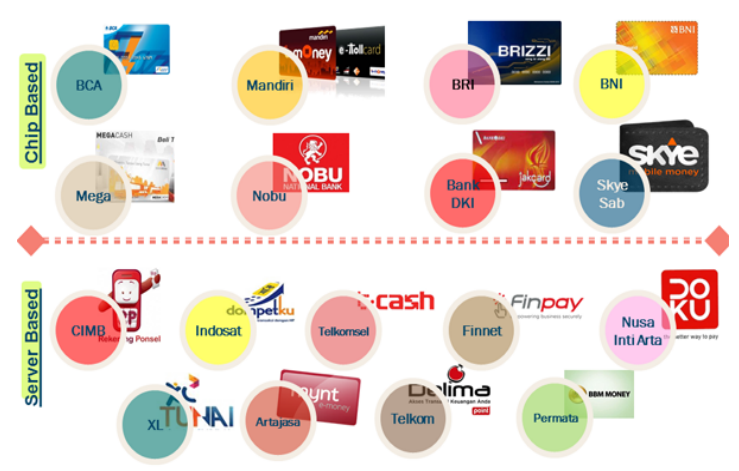

Gambar 2. Produk fintech yang masuk dalam kategori e-money ${ }^{2}$

Chip based adalah e-money yang berupa kartu fisik karena terdapat chip sebagai teknologi transaksinya yang kemudian diolah melalui server dari penyedia jasa tersebut. Produk fintech yang termasuk dalam kategori chip based adalah Mandiri e-money, BNI Tap Cash, BCA, dan sebagainya. Server based adalah e-money yang berupa aplikasi yang biasanya harus terpasang pada smartphone pengguna untuk dapat bertransaksi. Produk fintech yang termasuk dalam kategori server

nontunai/unik/Contents/Default.aspx, diakses tanggal 24 Maret 2020. 
based adalah Telkomsel Cash (T-Cash), Doku Wallet, XL Tunai, dll.

Berdasarkan Peraturan Bank Indonesia Nomor 18/17/PBI/2016 tentang penyelenggara e-money, terdapat 15 bank dan 38 perusahaan teknologi dan komunikasi yang masuk dalam daftar penyelenggara e-money per tanggal 11 November $2020^{3}$. Salah satu produk e-money server based yang sangat populer di Indonesia adalah OVO yang dibuat oleh PT. Visionet Internasional, yang sekarang telah menyatakan bahwa produk mereka telah dikategorikan sebagai e-wallet (dompet digital).

E-wallet sendiri merupakan e-money server based, yang kemudian lebih dikenal sebagai dompet digital. Ini karena platform tersebut dapat menyimpan uang yang dengan jumlah yang lumayan banyak, yakni antara Rp2.000.000,- dan Rp10.000.000,- jika pengguna meningkatkan (upgrade) akun mereka ke level premium, maka pengguna akan mendapatkan banyak fasilitas tambahan, seperti transfer antar pengguna OVO dan bank, saldo limit dari Rp2.000.000,- menjadi Rp10.000.000,-, dapat menentukan perencanaan investasi dan lain sebagainya tergantung kebijakan setiap penyedia jasa.

E-wallet di Indonesia kebanyakan digunakan oleh kalangan millenial karena $e$ wallet itu sendiri merupakan teknologi fintech terbaru yang menawarkan sistem pembayaran instan yang hadir di tengah masyarakat. Generasi millenial terkesan sangat konsumtif dalam berbelanja karena berbelanja dengan menggunakan $e$-wallet itu memudahkan, cepat dan efisien, sementara generasi millenial cenderung menyukai hal-hal yang bersifat instan.

\section{E-wallet: Sumber Informasi, Fitur, dan Penggunaan}

E-wallet adalah sebuah perangkat elektronik, layanan jasa, atau bahkan program perangkat lunak (aplikasi) yang memungkinkan para penggunanya untuk melakukan transaksi secara online dengan pengguna lainnya untuk

\footnotetext{
3 https://www.bi.go.id/id/sistempembayaran/informasi-perizinan/uangelektronik/penyelenggara-
}

membeli barang dan jasa. ${ }^{4}$ Bagaimana mahasiswa mendefinisikan e-wallet? Pipi (22 tahun) menganggap bahwa e-wallet adalah uang yang disimpan secara elektronik dan dapat digunakan secara elektronik. Sementara Wenny (18 tahun) berpendapat bahwa $e$ wallet adalah tempat pembayaran online, pembayaran yang mudah dan dapat dilakukan dimana saja. Dari mana mereka memeroleh informasi tentang e-wallet?

\section{Sumber Informasi}

Iklan merupakan cara agar suatu produk dapat diketahui oleh konsumen. Di era sekarang ini, iklan dapat ditayangkan di berbagai media. Pada awal pembuatan aplikasi e-wallet, perusahaan penyedia layanan tersebut mulai memperkenalkan produk mereka melalui iklan di beragam media dan menjadi sumber informasi bagi mahasiswa.

Bagi mahasiswa, iklan merupakan sumber informasi tentang $e$-wallet, mulai dari iklan di media sosial, televisi, hingga aplikasi transportasi online, sebagaimana yang akan dibahas berikut ini.

Dalam kehidupan sehari-hari, mahasiswa banyak menghabiskan waktu mereka di dunia maya, seperti media sosial. Iklan mengenai e-wallet juga ditayangkan secara masif di media sosial, seperti Youtube, Instagram, dan Facebook (lihat Gambar 3). Dengan ditayangkannya iklan di media sosial, maka bagi pengguna media sosial, informasi tentang $e$-wallet dapat dengan mudah diakses. Nunu (19 tahun), berpendapat bahwa dia pertama kali mengetahui tentang $e$-wallet saat sedang menonton video di Youtube. Iklan tentang $e$-wallet terus bemunculan saat sedang asyik menonton video tersebut.

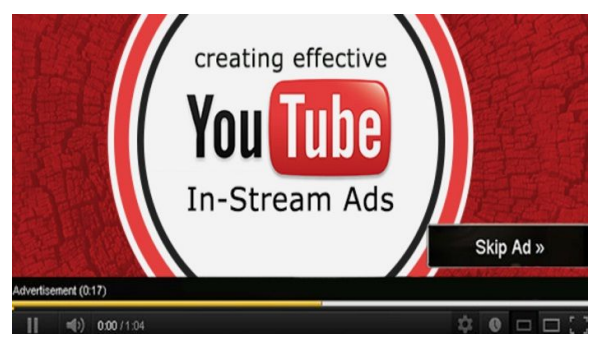

berizin/Contents/Default.aspx, diakses tanggal 11 Desember 2020.

${ }^{4}$ https://divedigital.id/apa-itu-e-wallet/, diakses tanggal 1 Desember 2020. 
Gambar 3. Iklan saat streaming pada youtube ${ }^{5}$

Televisi adalah media elektronik lainnya sebagai sumber informasi tentang $e$ wallet terhadap mahasiswa. Sebagai salah satu media hiburan utama bagi masyarakat di Indonesia, menayangkan iklan sebuah produk dapat menjadi sebuah langkah yang tepat untuk memperkenalkan brand mereka. Pipi (23 tahun) dan Nunu (19 tahun), misalnya, berpendapat serupa bahwa mereka mengetahui e-wallet pertama kali dari iklaniklan yang ditayangkan di televisi saat sedang jeda iklan program yang sedang ditayangkan (lihat Gambar 4).

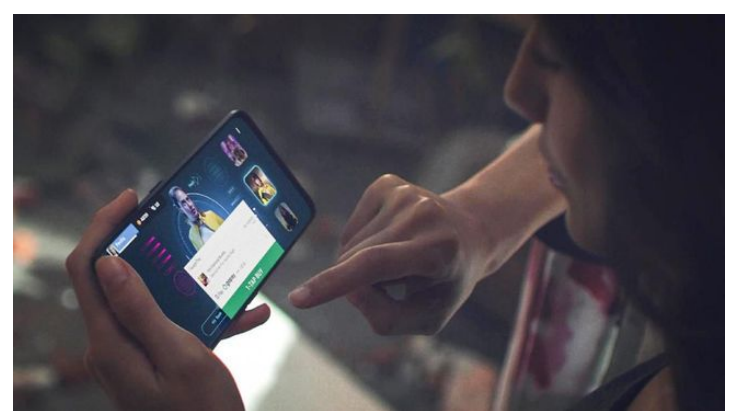

Gambar 4. Iklan Gopay pada sesi jeda iklan di televisi ${ }^{6}$

Aplikasi transportasi online adalah sumber informasi lainnya tentang e-wallet, dan dua aplikasi yang populer di kalangan mahasiswa adalah Gojek dan Grab. Selain itu, kedua aplikasi ini bekerja sama dengan aplikasi transportasi online sebagai paket yang tidak terpisahkan satu sama lain. Heny (21 tahun), misalnya, mulai mengetahui $e$-wallet dari aplikasi Gojek, yaitu Gopay. Namun saat itu ia belum begitu memahami cara penggunaannya. Kemudian saat beralih ke aplikasi ojek online lainnya, yaitu Grab, dia mulai untuk mempelajari OVO yang kebetulan adalah mitra dari Grab.

\section{Fitur E-wallet}

Aplikasi $e$-wallet memiliki beragam fitur. Adapun fitur yang terdapat pada e-wallet adalah premium, merchant yang memiliki

\footnotetext{
${ }^{5} \mathrm{https}: / /$ www.recode.id/youtube-hapus-fitur-lewatiiklan/. Diakses pada tanggal 29 desember 2020 6

https://www.cnnindonesia.com/teknologi/20191205125 349-190-454404/aksi-bela-diri-pevita-pearce-di-iklan-
}

ribuan outlets, promo (promosi), top ups, pembayaran tagihan \& isi pulsa, menyimpan kartu bank, dan mentransfer dan menarik saldo, sebagaimana yang akan dibahas berikut ini.

Fitur premium memang hampir dimiliki oleh setiap produk e-wallet yang ada di Indonesia, di mana ketika pengguna tidak melakukan upgrading, pengguna hanya dapat menyimpan saldo dengan batas (limit) Rp2.000.000,-. Namun, jika pengguna melakukan upgrading ke akun premium, maka limit top up saldo dapat mencapai Rp.10.000.000,-, serta mendapat keuntungan lainnya, seperti simpan kartu ATM (lihat Gambar 5).

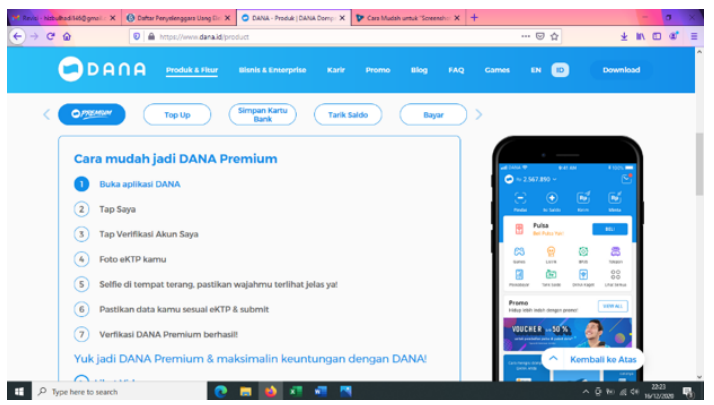

Gambar 5. Fitur Premium pada DANA ${ }^{7}$

Merchant juga merupakan aspek yang sangat penting bagi perusahaan $e$-wallet karena ketika outlet yang diajak untuk bermitra banyak, maka peluang masyarakat untuk menggunakan produk mereka juga bertambah besar. Banyak merchant yang menjadi mitra $e$ wallet di Indonesia, khususnya di kota-kota besar. DANA, misalnya, bermitra dengan Cinema XXI dengan memberikan diskon $50 \%$ untuk pembelian tiket menonton film. Hal seperti ini menarik perhatian mereka yang sangat gemar untuk menonton film di bioskop dengan menggunakan $e$-wallet tersebut, meski hanya untuk menggunakan promonya saja. Kerjasama semacam ini memicu orang untuk menggunakan e-wallet. Gambar 6 berikut ini adalah salah satu fitur dari OVO, yaitu merchant $60.000(+/)$ outlets.

gopay-bikin-terkesima. Diakses pada tanggal 29 desember 2020.

7 Hasil Screenshot pada PC, namun merujuk pada https://www.dana.id/product, diakses tanggal 16 Desember 2020. 


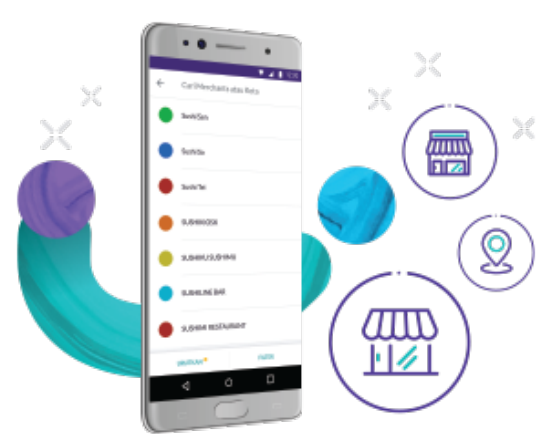

Gambar 6. Salah satu fitur dari OVO

Ini menunjukkan bahwa merchant (unit usaha/pedagang) juga merupakan aspek yang sangat penting bagi perusahaan $e$-wallet karena ketika merchant yang diajak untuk bermitra banyak, maka peluang fitur e-wallet juga beragam sesuai dengan kebutuhan masyarakat.

Fitur promosi (promo) adalah fitur terkait promo-promo yang diberikan oleh OVO kepada pengguna, yang berupa cashback, diskon, buy one get one dll., tergantung kesepakatan antara merchant dan OVO. Promo yang diberikan kadang dalam waktu tertentu yang telah ditentukan oleh merchant atau limited offers dimana sewaktu-waktu diberikan secara eksklusif kepada pengguna baru atau pengguna lama OVO.

Promo yang ditawarkan oleh aplikasi tersebut membuat kedua belah pihak mendapatkan keuntungan, pengguna $e$-wallet mendapatkan keuntungan dari tiket promo dan layanan khusus, sementara penyedia aplikasi mendapatkan keuntungannya dari penggunaan produk. Berikut promo yang diberikan jika membeli tiket di TIX ID yang dibayar melalui DANA (lihat Gambar 7).

\footnotetext{
${ }^{8}$ https://ovo.id/features, diakses tanggal 23 Maret 2020.

9 https://www.tix.id/\#promotion, diakses tanggal 25 Maret 2020.
}

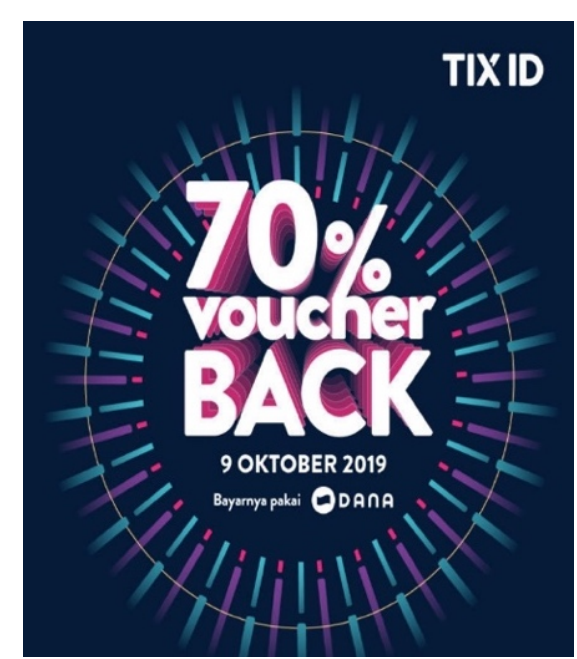

Gambar 7. Voucher tiket bioskop di TIX $\mathrm{ID}^{9}$

DANA, misalnya, bermitra dengan Cinema XXI. Melalui kemitraan ini, DANA memberikan diskon $50 \%$ untuk pembelian tiket menonton film di bioskop. Hal seperti ini dapat membuat kalangan anak muda yang sangat gemar untuk menonton film di bioskop menggunakan e-wallet tersebut. Desy (20 tahun), yang sering menonton di bioskop, yang jia ika menggunakan DANA, ia mendapatkan diskon $50 \%$ untuk pembelian tiket kedua, dan layanan untuk membeli advance tiket ${ }^{10}$ (preorder). Meskipun ini hanya untuk menggunakan promosinya (promo) saja, hal ini menstimulasi orang untuk menggunakan $e$ wallet.

Fitur top up memungkinkan pengguna untuk top up saldo OVO cash di mana saja dan kapan saja. Pengguna dapat melakukan top up saldo melalui ATM, m-banking, internet banking, debit card, atau melalui merchant yang telah bekerja sama dengan OVO, seperti Alfamart dll (lihat Gambar 8).

\footnotetext{
${ }^{10}$ Layanan untuk membeli tiket beberapa hari sebelum jadwal tayang.
} 


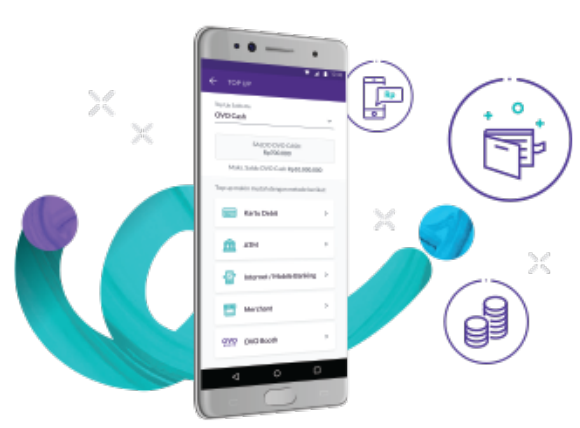

Gambar 8. Fitur top up praktis pada OVO $^{11}$

Fitur lainnya adalah fitur pembayaran tagihan dan pembelian pulsa. Fitur ini merupakan fitur yang memungkinkan pengguna untuk membayar tagihan (seperti listrik, air PAM, telepon, internet dan asuransi) dan membeli pulsa in-app purchase (beli pulsa melalui aplikasi) (lihat Gambar 9). Melalui fitur ini, pengguna dapat melakukan pembayaran kapan dan dimana saja dengan sekali klik.

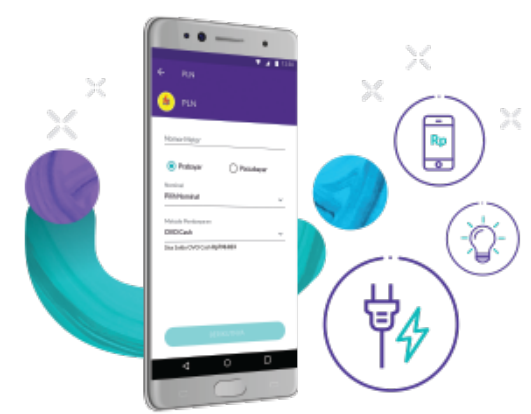

Gambar 9. Fitur bayar tagihan \& isi pulsa pada OVO ${ }^{12}$

Fitur menyimpan kartu bank adalah fitur lain yang merupakan fitur yang memungkinkan pengguna untuk menyimpan kartu debit dan kredit secara bersamaan dan pengguna dapat menggunakan kartu tersebut tanpa harus membawa kartu fisik dari debit dan kreditnya (lihat Gambar 10). Fitur ini merupakan salah satu andalan dari DANA dalam melakukan promosi kepada masyarakat di Indonesia yang cenderung lebih menyukai bertransaksi melalui kartu kredit dan debit mereka.

${ }^{11} \mathrm{https}: / /$ ovo.id/features, diakses tanggal 31 Maret 2020.

12 https://ovo.id/features, diakses tanggal 31 Maret 2020.

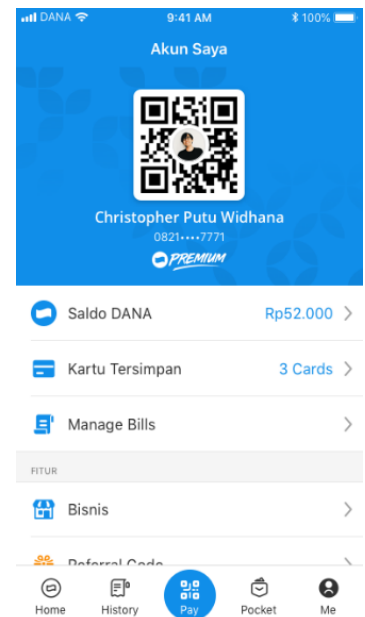

Gambar 10. Fitur simpan kartu bank dari DANA $^{13}$

Fitur mentransfer dan menarik saldo adalah fitur yang juga ada di e-wallet lainnya. Namun yang membedakannya adalah pada merchant mitra dari e-wallet masing-masing. Pengguna dapat melakukan transfer saldo $e$ wallet mereka ke akun e-wallet orang lain dengan brand sejenis. Selain itu, pengguna dapat menarik saldo mereka di merchant yang bermitra (lihat Gambar 11).

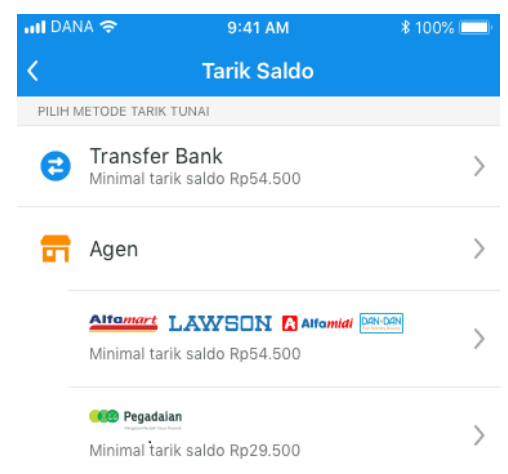

Gambar 11. Fitur transfer dan tarik saldo dari DANA $^{14}$

\section{Penggunaan E-wallet}

Meskipun e-wallet dinilai cukup mudah untuk digunakan, pada kenyataannya masih banyak mahasiswa yang belum begitu memahami secara rinci tentang tata cara penggunaan $e$ wallet. Ketika ditanyakan tentang bagaimana

\footnotetext{
${ }^{13}$ https://dana.id/product, diakses tanggal 31 Maret 2020.

${ }^{14}$ https://dana.id/product, diakses tanggal 31 Maret 2020.
} 
cara untuk mengakses e-wallet, jawabannya beragam. Ada yang menjawab dengan pasti, ada yang masih ragu-ragu, dan ada yang tidak dapat menjawabnya dengan tepat.

Mala (23 tahun) mengungkapkan bahwa langkah awal adalah dengan mengunduh aplikasinya. Kemudian, ketika itu, ia didampingi oleh costumer service-nya (CS) karena untuk pendaftaran pertama membutuhkan KTP dan swafoto. Cara yang dikemukakan oleh Mala merupakan cara mendaftar bagi pengguna di awal hadirnya booth OVO di Makassar. Pendaftaran masih harus dilaksanakan melalui booth OVO yang ada di pusat perbelanjaan yang ada di kota Makassar.

Namun sekarang untuk menggunakan e-wallet caranya lebih simpel, seseorang tinggal mengunduh aplikasi tersebut di Playstore bagi pengguna Android dan di Appstore bagi pengguna iOS. Ollaf (19 tahun), misalnya, mengatakan bahwa cara mengunduh aplikasi tersebut cukup mudah, yaitu dengan membuka aplikasi market bawaan dari handphone, kemudian mengunduh aplikasi $e$ wallet yang ingin digunakan. Pernyataan serupa diungkapkan oleh Heny (21 tahun), bahwa pertama-tama orang harus memastikan data koneksi di handphone tersebut aktif, kemudian membuka app market dan mengunduh aplikasi e-wallet yang diinginkan.

Bagi pengguna yang ingin meningkatkan (upgrade) dari level reguler ke level premium, maka pengguna tidak perlu lagi untuk mendaftar di booth yang ada di pusat perbelanjaan, tapi ia dapat melakukan upgrade akunnya langsung melalui aplikasi di perangkat gadget mereka masing-masing. Tata cara aplikasi DANA ada di website resminya, yang menjelaskan tentang langkah-langkah penggunaan secara sederhana dan jelas, yang secara rinci dapat dilihat pada Gambar 12 berikut ini.

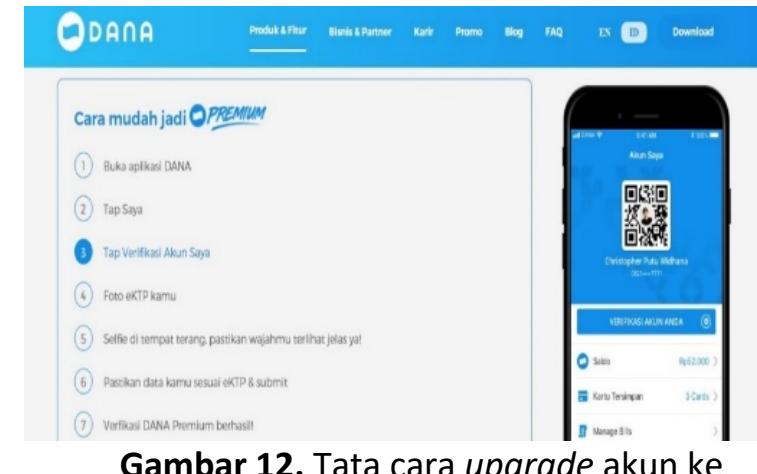

Gambar 12. Tata cara upgrade akun ke premium $^{15}$

Tata cara dari gambar di atas dimulai dengan membuka aplikasi DANA. Kemudian memilih ikon "tap saya". Lalu memilih "tap verifikasi akun saya". Setelah itu, mengambil gambar KTP. Ini diikuti dengan memastikan data sesuai dengan data di e-KTP sebelum akhirnya dikirim (submit).

Sinta (19 tahun) mengungkapkan bahwa penggunaan aplikasi membutuhkan jaringan internet, kemudian top up juga dapat dilakukan melalui aplikasi Gojek dari pengemudi. Hal tersebut dapat memberi keuntungan pada pengemudi, karena ketika pengguna melakukan top up pada pengemudi, maka pengemudi akan mendapatkan bonus.

Ada cara yang beragam untuk melakukan pembayaran/pembelian tagihan dalam apikasi. Ollaf (19 tahun) mengatakan bahwa cara pembayaran pada aplikasi Gojek bisa dilakukan dengan membuka salah satu fitur dalam aplikasi, seperti GoFood. Kemudian memilih metode pembayaran cash atau melalui deposit Gopay atau fitur-fitur lainnya. Pipi (23 tahun) mengungkapkan bahwa untuk melakukan pembayaran, ia hanya membutuhkan scan barcode karena nominal sudah jelas dalam aplikasi dan setelah itu saldo akan terpotong secara otomatis.

\footnotetext{
${ }^{15} \mathrm{https} / / /$ dana.id/product, diakses tanggal 25 Maret 2020 .
} 


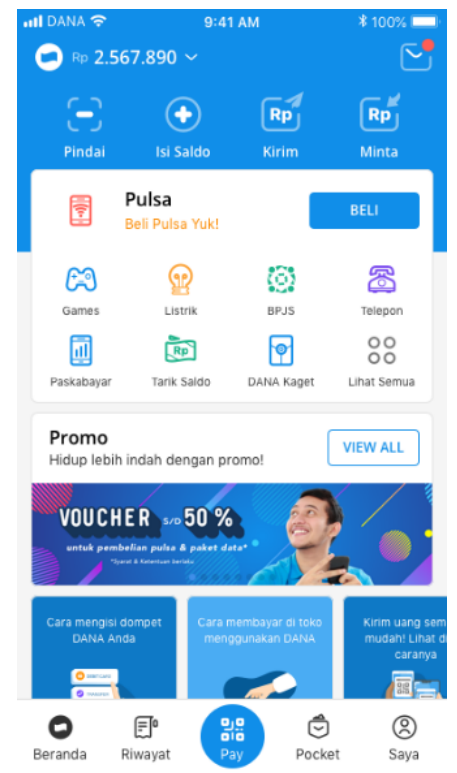

Gambar 13. Tampilan utama dari aplikasi DANA $^{16}$

Gambar di atas merupakan tampilan utama dari aplikasi DANA, dan melaluinya segala fitur dapat diakses dari tampilan ini. Langkah yang perlu dilakukan adalah mencari layanan yang ingin digunakan. Misalnya, jika seseorang ingin memesan makanan, ia tinggal mencari produk Gofood, yang hanya dapat diakses melalui aplikasi Gojek yang langsung terintegrasi dengan $e$-wallet-nya sendiri, yaitu Gopay. Kemudian dilakukan scanned barcode dan dibayar via aplikasi $e$-wallet tersebut (lihat Gambar 14).
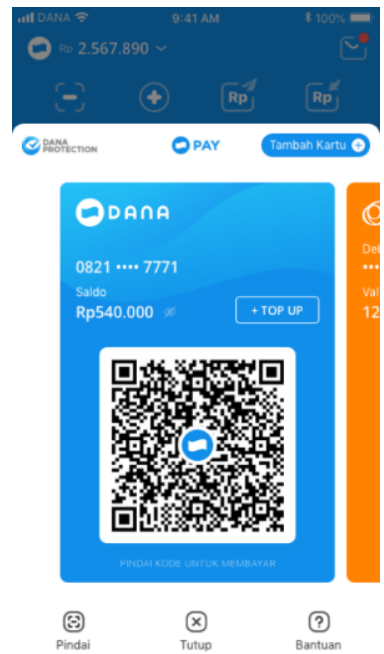

Gambar 14. Tampilan scanned barcode pada aplikasi DANA ${ }^{17}$

${ }^{16}$ https://dana.id/product, diakses tanggal 26 Maret 2020.

17 https://dana.id/product, diakses tanggal 26 Maret 2020.
Ada mahasiswa yang menggunakan $e$ wallet hanya sebagai metode pembayaran online untuk kepentingan transportasi semata. Ollaf (19 tahun) menggunakan e-wallet setiap hari, dengan memesan ojek online jika ingin bepergian kemana-mana. Ada pula mahasiswa yang selalu menggunakan $e$-wallet setiap kali memesan makanan secara online jika sedang berada di rumah, seperti yang dilakukan Heny (21 tahun). Setiap kali ingin makan, maka dia akan memesan makanan tersebut melalui aplikasi ojek online dan membayar melalui aplikasi atau saldo dari e-wallet. Mala (23 tahun) menggunakan e-wallet setiap hari paling sedikit sekali sehari untuk transportasi atau makan. Desy (20 tahun), menggunakan $e$ wallet untuk membeli snack atau minuman ketika berada di mall, dan ketika ingin menonton di bioskop.

Selain untuk pembayaran transportasi dan makanan, ada mahasiswa yang menggunakan e-wallet untuk berbagai kebutuhan sehari-hari. Ollaf (19 tahun), misalnya, seringkali menggunakan e-wallet untuk memenuhi beragam kebutuhan hidup sehari-harinya, seperti: membeli makanan, memesan ojek online, menonton bioskop, membeli voucher game online, pulsa, token listrik, dan bayar air PAM.

Pengguna yang bijak biasanya menggunakan e-wallet dalam memenuhi kebutuhan yang dinilai penting untuk seharihari, apalagi pihak e-wallet masih dalam tahap "bakar uang"18, dengan memberikan layanan terbaik mereka meski tidak mendapatkan keuntungan yang begitu signifikan. Hal ini dilakukan demi menarik minat pengguna, membangun kepercayaan (trust) agar dapat menjadi perusahaan pilihan nomor satu di masyarakat, dan mendominasi valuasi pasar di Indonesia. Kenapa mereka menggunakan $e$ wallet?

\section{Alasan Penggunaan E-Wallet}

Dalam melakukan transaksi perbelanjaan, banyak metode yang dapat digunakan oleh

\footnotetext{
18 "Bakar uang" adalah istilah yang digunakan untuk sebuah kegiatan yang menghabiskan banyak uang dengan proses bisnis tertentu, seperti akuisisi pasar dan marketing.
} 
konsumen tergantung metode seperti apa yang disediakan oleh pihak merchant/toko. Setiap metode pembayaran memiliki kelebihan dan kekurangannya masing-masing, yang penting merchant atau penyedia barang tersebut tidak merugikan konsumen. Tiga alasan mahasiswa menggunakan e-wallet dalam bertransaksi yakni, promo (promosi), kenyamanan dan kemudahan.

\section{Promo}

Promosi (disingkat promo) merupakan hal yang paling diminati oleh mahasiswa, seolah menjadi daya tarik yang besar bagi mereka. Setiap ingin membeli segala sesuatu harga dan promo sangat signifikan menjadi bahan pertimbangan karena dengan demikian mereka dapat menghemat pengeluaran, terutama mahasiswa perantau.

Ini diperkuat oleh temuan Silaen dan Prabawani (2019) dalam studinya terkait produk OVO, bahwa di antara tiga aspek yang paling dominan (kemudahan, manfaat, dan promosi), promosi berpengaruh sangat signifikan dalam pengambilan keputusan, terutama jika promo dilakukan secara berulang yang pada akhirnya mengarah pada terciptanya loyalitas merek dan mengikat pembeli pada produsen tertentu.

Banyak pengguna e-wallet menganggap bahwa promo dari merchant mitra e-wallet cukup beragam dan menggiurkan. Desy (20 tahun), misalnya, beranggapan bahwa salah satu kelebihan menggunakan e-wallet adalah karena memiliki banyak promo. Di antara promo yang ditawarkan adalah cashback untuk pembelian dengan nilai tertentu, discounted price (harga diskon), atau bahkan buy one get one free (beli satu gratis satu), dll. Ini menunjukkan bahwa promosi dari merchant sangat memengaruhi pembeli untuk terus mengonsumsi barang atau jasa yang ditawarkan.

Pusat perbelanjaan seperti mall yang ada di kota-kota besar seperti halnya yang ada di kota Makassar banyak bekerja sama dengan berbagai macam merchant, mulai dari merchant kelas atas, seperti Pizza Hut, hingga merchant kelas menengah, seperti J.CO,

19 https://ovo.id/features, diakses tanggal 31 Maret 2020.
UPNORMAL, dan Solaria. Merchant kelas menengah biasanya yang paling banyak memberikan promo agar dapat bersaing dengan merchant kelas atas dengan tujuan untuk mendapatkan trust dari pelanggan.

Hal ini menjadi kabar yang sangat ditunggu oleh pengguna e-wallet karena berbagai merchant tersebut mengetahui bahwa kebanyakan dari pengunjung mall adalah mereka yang berusia muda hingga dewasa, generasi millenial, dan pengguna teknologi dalam kehidupan sehari-hari mereka. Merchant "membaca" peluang yang besar jika memberikan promo kepada pelanggan yang menggunakan e-wallet sebagai metode pembayaran mereka.

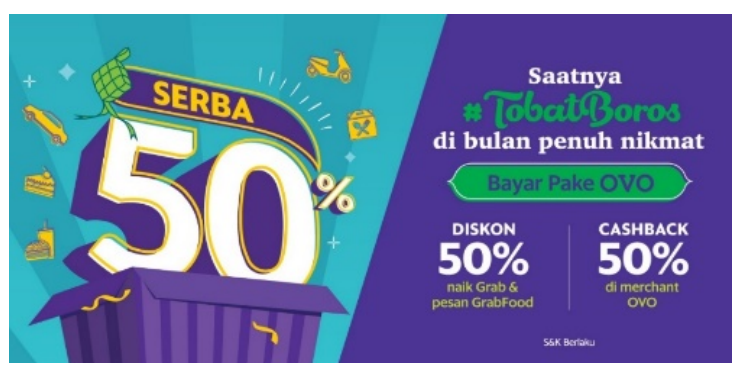

Gambar 15. Promo serba 50\% dari OVO ${ }^{19}$

Gambar 15 di atas merupakan contoh promo yang diberikan oleh merchant yang bergerak di bidang jasa transportasi online, Grab. Promo diberikan jika menggunakan layanan dari Grab, baik itu Grab Bike maupun Grab Food dan akan mendapat diskon 50\% dan ada opsi cashback 50\% jika menggunakan OVO sebagai metode pembayaran pada merchant mitra OVO. Sebagai pengguna, Heny (21 tahun) menganggap bahwa aplikasi OVO memiliki banyak diskon ketika ia menggunakan ojek online dari Grab. Kemudian jika ia membayar dengan menggunakan OVO, maka ia akan langsung mendapatkan diskon, dan juga mendapatkan cashback berupa poin yang nantinya dapat digunakan layaknya saldo utama. Dengan demikian, ia mendapatkan dua keuntungan sekaligus, yakni diskon 50\% dan cashback $50 \%$ yang baru dapat digunakan pada transaksi berikutnya. Gambar $\mathbf{1 6}$ di bawah ini merupakan contoh promo yang diberikan oleh 
merchant yang bergerak di bidang minuman yang dijual di pusat perbelanjaan.

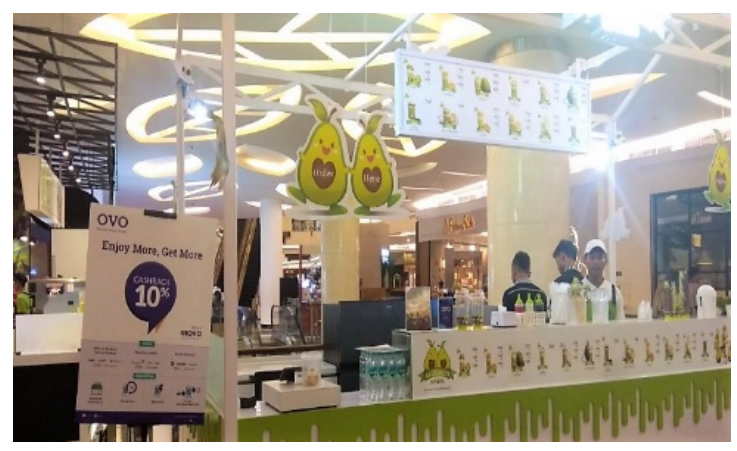

Gambar 16. Promo cashback untuk pengguna $\mathrm{OVO}^{20}$

Promo tidak hanya diberikan merchant di pusat perbelanjaan, promo juga banyak ditemukan di tempat lain seperti di SPBU. Misalnya, merchant memberikan cashback $10 \%$ setiap pembelian bahan bakar di outlet mereka (lihat Gambar 17).

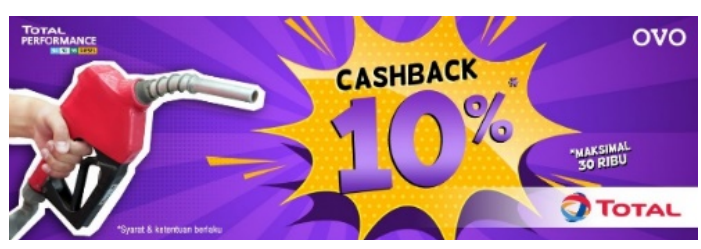

Gambar 17. Promo cash back untuk pembelian bahan bakar

Kemudian merchant dari e-commerce pun ikut mengambil bagian dalam memberikan promo bagi masyarakat yang ingin berbelanja online pada toko mereka melalui website maupun aplikasi pada smartphone (lihat Gambar 18). Promo yang diberikan tergantung merek dan jenisnya dan tergantung kesepakatan dari pihak brand yang bekerja sama dalam memromosikan produk mereka di situs belanja online merchant tersebut.

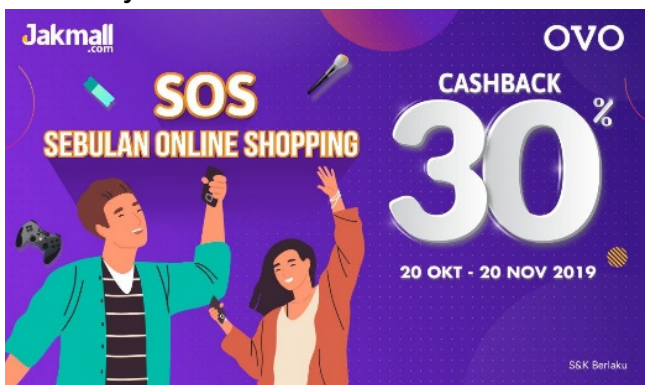

20 Mokapos.com, diakses tanggal 31 Maret 2020.
Gambar 18. Promo online shopping dari OVO $^{21}$

Promo memicu konsumen untuk berbelanja, namun dalam siklus perekonomian, jika merchant memberikan promo, maka merchant juga siap dengan resiko keuntungan berkurang untuk setiap produk. Tapi, jika produk dibeli dengan skala besar, maka keuntungan akan tetap berimbang.

\section{Kenyamanan (Convenience)}

Alasan kedua kenapa penggunaan e-wallet populer di kalangan mahasiswa adalah karena kenyamanan dalam penggunaannya. Sesuatu yang memberikan kenyamanan bagi pengguna dapat menjadi alasan yang kuat bagi yang bersangkutan untuk menggunakan produk itu dalam waktu yang lama. Desy (20 tahun), misalnya, menganggap bahwa pembayaran via $e$-wallet cukup cepat dan nyaman. Selain itu, orang dapat membayar dimana saja karena saldo juga dapat di top up melalui M-banking dari smartphone. Misalnya, jika Desy ingin melakukan top up saldo, ia tinggal membuka aplikasi M-banking melalui gadget-nya, kemudian memilih menu pembayaran atau transfer ke saldo e-wallet yang diinginkan. Menu pembayaran di setiap M-banking bisa berbeda-beda tergantung kerja sama antar kedua belah pihak (pihak bank dan e-wallet).

Kenyamanan penggunaan e-wallet akan membuat penggunanya menjadi konsumtif. Sri (21 tahun), misalnya, mengungkapkan bahwa: "Respon orang-orang di sekitar saya bahwa saya adalah orang yang banyak uang dan merasa kekinian, kadang juga dibilangi boros sama keluarga." Hal serupa diungkapkan oleh Irma (21 tahun), bahwa ia dijuluki pemboros oleh teman-temannya karena sering berbelanja online, terutama jika ada promo diskon atau cashback.

Namun, ada yang menganggap bahwa menggunakan $e$-wallet sebagai metode pembayaran justru tidak menjadikan penggunanya terlihat berlebihan dalam berbelanja. Bagi Wenny (19 tahun), hal itu tergantung bagaimana kita mengontrol diri kita (baca, misalnya, Subaramaniam 2020). Baginya penggunaan $e$-wallet justru membuatnya dapat menahan diri dan dapat menabung

${ }^{21}$ www.jakmal.com, diakses tanggal 2 April 2020. 
karena ia mendepositokan uangnya dalam $e$ wallet. Menurutnya, dengan penggunaan cash dalam berbelanja, ia justru menjadi boros karena ia memegang uang secara cash yang dapat dengan mudah ia belanjakan. Namun demikian, Wenny juga mengungkapkan bahwa penggunaan e-wallet bukan tanpa kelemahan. Misalnya, saat terjadi kegagalan sistem atau error, terbatasnya merchant untuk melakukan pengisian ulang saldo (top-up) yang tidak semasif seperti pengisian pulsa elektronik yang dapat dijumpai bahkan di ruko-ruko kecil yang berada dipinggir jalan. Tapi, menurutnya, hal ini dapat diatasi dengan melakukan top up melalui M-banking, tapi ia sendiri belum memilikinya.

Penggunaan e-wallet dalam bertransaksi dapat memberikan tren positif bagi penggunanya. Pengguna dapat melakukan berbagai transaksi perbelanjaan melalui aplikasi e-wallet yang diinginkan berkat kenyamanan bertransaksi. Ollaf (19 tahun) mengakui bahwa ia menggunakan e-wallet untuk berbagai kebutuhan sehari-harinya (seperti membeli makanan, menggunakan ojek online, menonton bioskop, top up dalam game, belanja online, beli pulsa, beli token listrik, dan bayar air PAM) karena ia malas menggunakan uang cash. Meskipun ia sering ditegur oleh teman-temannya karena boros menggunakan e-wallet, ia tidak mengindahkannya karena kenyamanan bertransaksi menjadi prioritasnya, terutama karena ia menggunakan e-wallet kebanyakan untuk kebutuhan primernya.

\section{Kemudahan (Ease to Use)}

Kemudahan dalam melakukan berbagai transaksi dapat menjadi alasan seseorang untuk menggunakan produk tertentu. Mahasiswa cenderung menyukai hal-hal yang mudah dalam penggunaannya karena dianggap cepat menyelesaikan pekerjaannya. E-wallet dikenal menawarkan kemudahan dalam pengoperasiannya. Desy (20 tahun) berpendapat bahwa penggunaan e-wallet itu mudah, praktis dan simple karena hanya bermodalkan hape dan dapat dilakukan dimana-mana.

\footnotetext{
${ }^{22}$ www.dana.id/product, diakses tanggal 2 April 2020.
}

Dalam kaitan dengan ini, studi
Manikan dan dan Jayakodi
mengemukakan bahwa pengguna mobile wallet dipengaruhi oleh sejumlah faktor, yakni harga lebih murah, sistem pembayaran yang mudah bagi penggunanya. Temuan studi ini memperkuat temuan Manikan dan Jayakodi, yakni kemudahan menggunakan e-wallet. Dalam kaitan dengan ini Sinta (19 tahun) menekankan bahwa dengan menggunakan $e$ wallet, ia tidak perlu membawa uang tunai, cukup dengan membawa handphone saja". Mala (22 tahun) menganggap bahwa e-wallet praktis dan mudah dalam penggunaannya. Wenny (19 tahun) secara lebih rinci menjelaskan bahwa pembayaran melalui $e$ wallet itu sangat mudah. Untuk melakukan pembayaran seseorang cukup memindai (scanned) barcode (QR Code) dan setelah itu secara otomatis deposit dalam e-wallet terpotong dengan sendirinya.

Teknologi terkini juga telah berbenah mengikuti perkembangan zaman yang menuntut segala sesuatu itu harus simpel dan mudah untuk digunakan. Apabila tidak mengikuti kebutuhan dari masyarakat, maka teknologi itu cenderung kurang dipertimbangkan untuk digunakan oleh konsumen. Gambar 19 menunjukkan tampilan dari fintech terbaru yakni e-wallet DANA yang sangat sederhana, namun memiliki banyak fitur yang menggiurkan.

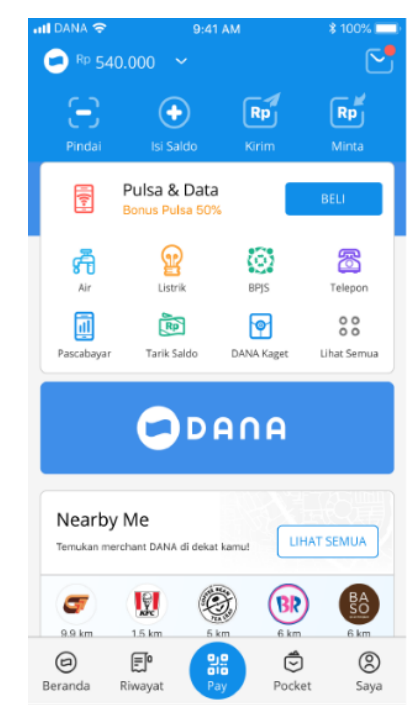

Gambar 19. Tampilan utama dari aplikasi DANA $^{22}$ 
Jika alasan promo, kenyamanan, dan kemudahan yang telah dikemukakan di atas, maka pertanyaan yang muncul adalah terkait dengan dapat/tidaknya e-wallet menggantikan posisi dompet fisik. Jawabannya masih ambivalen. Ada yang beranggapan bahwa posisi dompet fisik telah tergantikan oleh $e$ wallet, sebagaimana yang dikemukakan oleh Sri (21 tahun), bahwa "E-wallet sudah bisa menggantikan dompet konvensional karena kebanyakan orang saat ini telah menggunakan smartphone. Artinya, mereka telah memiliki akses untuk menggunakan e-wallet. Hal serupa juga dikemukakan oleh Wenny (19 tahun), bahwa ia merasa e-wallet telah dapat menggantikan dompet fisik karena kebanyakan orang menggunakan handphone, kemudian dalam handphone bisa install mobile banking, dan e-wallet, sehingga orang dapat menggunakannya untuk pembayaran.

Meskipun Desy, Ollaf, dan Heny adalah pengguna $e$-wallet, mereka tetap menganggap bahwa e-wallet belum dapat menggantikan dompet konvensional karena belum semua kebutuhan dapat difasilitasi oleh e-wallet. Misalnya, masih banyak restoran, tempat makan pinggir jalan, bengkel motor dan mobil yang belum bekerjasama untuk memfasilitasi penggunaan e-wallet, sehingga uang cash masih harus tetap tersedia jika berbelanja di tempat-tempat yang tidak memiliki fasilitas tersebut.

Dalam kaitan dengan berbagai pendapat di atas, Mala (22 tahun) beranggapan bahwa jika menaruh sesuatu yang berharga pasti akan menyimpannya di tempat yang juga berharga. Baginya, menyimpan uang di $e$ wallet lebih aman dari pada menyimpannya di dompet konvensional.

\section{Kesimpulan dan Rekomendasi}

E-wallet di kota Makassar telah berkembang sangat pesat dan digunakan oleh berbagai kalangan, termasuk mahasiswa sebagai generasi millenial. Beragam produk ditawarkan oleh penyedia jasa e-wallet, meskipun tidak semua produk tersebut digunakan oleh mahasiswa. Mahasiswa sebagai generasi millenial menjadi target pasar terbesar dalam memanfaatkan teknologi terbaru yang ada di sekeliling mereka, termasuk dalam penggunaan $e$-wallet yang sedang tren.

Pengetahuan mahasiswa tentang $e$ wallet berkaitan dengan dengan sumber informasi, fitur, dan tujuan penggunaannya. Iklan dari media sosial, televisi, dan aplikasi lain menjadi sumber informasi mahasiswa tentang $e$-wallet. E-wallet tidak saja dipahami sebagai tempat menyimpan uang secara elektronik, tapi juga sebagai sistem pembayaran digital dengan fitur yang beragam, seperti top up, pembayaran tagihan, menyimpan kartu bank, transfer dan menarik uang, dll. Mahasiswa menggunakan $e$-wallet untuk beragam tujuan, seperti membayar transportasi online, membeli makanan/minuman, membayar tagihan, dll.

Tiga alasan mendasar mahasiswa menggunakan e-wallet sebagai metode pembayaran, yakni karena adanya promo yang ditawarkan, kenyamanan dalam bertransaksi, dan kemudahan dalam pengoperasiannya. Namun, untuk menarik minat orang menggunakan e-wallet, para penyedia jasa harus bekerja sama dengan beragam merchant, yang promo-promonya semakin menarik minat penggunanya untuk menggunakan $e$-wallet dalam berbelanja. Dalam menggunakan e-wallet, mahasiswa tidak saja merasakan kenyamanan dalam berbelanja, tapi juga kenyamanan dalam pembayaran karena dapat dilakukan dimana saja selama pengguna terhubung dengan internet. Berbagai kemudahan yang ditawarkan oleh e-wallet salah satunya adalah tampilan aplikasi yang sederhana yang membuat banyak pengguna dapat memahami cara pengoperasiannya dengan cepat.

Terlepas dari berbagai alasan yang mendasari kenapa mahasiswa menggunakan $e$ wallet, namun sistem pembayaran seperti ini sangat rentan terhadap aksi peretasan (hacking) oleh orang-orang yang tidak bertanggung jawab. Hal ini dapat berpotensi menjadi kelemahan terbesar pada e-wallet di kemudian hari jika developer dari aplikasi tersebut meremehkan dan menyepelekan keamanan data pengguna. Ini sangat tergantung pada proteksi service provider atau bank dan kehati-hatian penggunanya.

Pemerintah dapat mendukung penerapan e-wallet dengan mewajibkan 
merchant menengah ke atas untuk menyediakan opsi pembayaran via e-wallet. Hal ini dapat menstimulasi berbagai kalangan untuk menggunakan e-wallet dalam bertransaksi. Namun pemerintah juga perlu memerhatikan sistem keamanan dalam melakukan transaksi digital agar tidak merugikan masyarakat. Dalam hal ini pemerintah dapat melakukan fungsi pengawasan melalui OJK (Otoritas Jasa Keuangan). Bagi penyedia jasa e-wallet diharapan dapat memberikan fitur berupa data statistik agar pengguna dapat mengetahui total pengeluaran mereka pada aplikasi tersebut beserta jumlah penghematan yang diperoleh dari promo yang diperoleh agar pengguna juga dapat lebih bijak dalam menggunakan aplikasi tersebut.

\section{Daftar Pustaka}

Anjelina. 2018. "Persepsi Konsumen Pada Penggunaan E-Money", Journal of Applied Managerial Accounting, 2(2):219-231.

Budiati, I.; Susianto, Y.; Adi, P. W.; Ayuni, S.; Reagan, A, H.; Larasaty, P.; Setiyawati, N.; Pratiwi, I, A. dan Saputri, G. V. 2018. Profil Generasi Milenial Indonesia. Jakarta: Kementerian Pemberdayaan Perempuan dan Perlindungan Anak.

Creswell, J. W. 2010. Research Design Pendekatan Kualitatif, Kuantitatif dan Mixed; (Cetakan I). Yogyakarta: Pustaka Pelajar.

Faridhal, M. 2018. "Analisis Transaksi Pembayaran Non-Tunai Melalui Ewallet: Perspektif Dari Modifikasi Model Unified Theory of Acceptance and Use of Technology", Jurnal IImiah Mahasiswa FEB, 7(2):1-17.

Fransiska dan Suyasa, S. Y. T. P. 2005. "Perbandingan Perilaku Konsumtif Berdasarkan Metode Pembayaran", Jurnal Phronesis, 7(2):172-199.
Hidayatullah, S., Warris, A., Devianti, C, R., Sari, R, S., Wibowo, A, I. Dan Made, P. 2018. "Perilaku Generasi Milenial Dalam Menggunakan Aplikasi Go-Food", Jurnal Manajemen \& Kewirausahaan, 6(2):240-249.

Juditha, C. dan Darmawan J. 2018. "Penggunaan Media Digital Dan Partisipasi Politik Generasi Milenial", Jurnal Penelitian Komunikasi dan Opini Publik, 22(2):94-108.

Kusnawan, A., Silaswara, D., Andy dan Sefung, T. 2019. "Pengaruh Diskon Pada Aplikasi e-Wallet Terhadap Pertumbuhan Minat Pembelian Impulsif Konsumen Milenial di Wilayah Tangerang", Jurnal Sains Manajemen, 5(2):137-160.

Manikandan dan Jayakodi, M.J. 2017. “An Emprical Study On Consumer Adoption Of Mobile Wallet With Special Reference To Chennai City", International Journal of ResearchGranthaalayah, 5(5):107-115.

Marita, S. L. 2012. "Metode Pembayaran Belanja Dengan E-Commerce", Cakrawala, 12(2):105-113.

Maulinda, G. D. 2016. “Analisis Trust Dalam Penggunaan E-Money Sebagai Teknologi Konsumsi : Studi Mengenai Penggunaan E-Money Kelas Menengah-Atas dan Menengah-Bawah Mahasiswa Fakultas Ilmu Sosial dan IImu Politik Universitas Indonesia", Indonesian Journal of Sociology and Education Policy, 1(1):61-79.

Mulyasari, H., Bi, T. T., \& Wijaya, M. B. A. 2014. "Analisis Jenis Sistem Pembayaran Elektronik Dalam Transaksi ECommerce di Indonesia". Seminar Nasional Teknologi Informasi dan 
Komunikasi 2014 (SENTIKA 2014).

Yogyakarta, 15 Maret 2014.

Rudiwantoro, A. 2018. "Langkah Penting Generasi Millenial Menuju Kebebasan Finansial Melalui Investasi", Jurnal Moneter, 5(1):44-51.

Silaen E. dan Prabawani B. 2019. "Pengaruh Persepsi Kemudahan Menggunakan EWallet Dan Persepsi Manfaat Serta Promosi Terhadap Minat Beli Ulang Saldo E-Wallet OVO", Jurnal IImu Administrasi Bisnis, 8(4):155-163.

Subaramaniam, K.; Kolandaisamy, R.; Bin Jalil, A.; Kolandaisamy, I.; dan "The Impact of E-Wallets for Current Generation", Journal of Advance Research in
Dynamical \& Control Systems, Special Issue, Februari, 12(1):751-759. https://www.researchgate.net/publicat ion/339236716 The Impact of E-

Wallets for Current Generation, diakses tanggal 15 Desember 2020.

Suharni. 2018. "Uang Elektronik (E-money) Ditinjau dari Perspektif Hukum dan Perubahan Sosial", Jurnal Spektrum Hukum, 15(1):15-43.

Sulistyawati, D. dan Santosa, I. 2019. “Pengaruh Perilaku Budaya Generasi Milleniial Menghadapi Revolusi Industri Terhadap Ruang Hunian Pribadi Dengan Studi Kasus 'One Room Living' Mahasiswa", Jurnal Desain Indonesia, 1(1):24-30. 